\title{
Presentación: Los partidos comunistas de Europa occidental ante la integración europea
}

\section{Foreword: The communist parties of Western Europe in the face of European integration}

\author{
Salvador Forner Muñoz \\ Universidad de Alicante, España \\ salvador.forner@ua.es \\ https://orcid.org/0000-0001-5428-9557 \\ Heidy Cristina Senante Berendes \\ Universidad de Alicante, España \\ hc.senante@ua.es \\ https://orcid.org/0000-0002-9532-8994
}

Recibido: 27/11/2021

Aceptado: 30/11/2021

Cómo citar este artículo: FORNER MUÑOZ, Salvador; SENANTE BERENDES, Heidy Cristina (2022). Presentación del dossier. Los partidos comunistas de Europa occidental ante la integración europea. Pasado y Memoria. Revista de Historia Contemporánea, (24), pp. 1-9, https://doi.org/10.14198/PASADO2022.24.00

Financiación: Este dosier monográfico se enmarca en el proyecto europeo con referencia 610735-EPP-1-ES- EPPPJMO-CHAIR.

La historiografía sobre la relación de los partidos comunistas de Europa occidental con la Comunidad Europea/Unión Europea ha abordado con amplitud los decenios iniciales del proceso de integración en el marco de la política de bloques y de los planteamientos de la Unión Soviética ante dicho proceso. El comunismo occidental se mostró inicialmente unánime en su rechazo de la integración comunitaria considerando toda cooperación económica

C2022 Salvador Forner Muñoz y Heidy Cristina Senante Berendes 
y política entre los países occidentales como un acto de agresión contra la Unión Soviética. El grueso de la argumentación comunista contra el proceso integrador, aunque con ligeros matices relacionados con las distintas situaciones nacionales, coincidía plenamente con la posición adoptada por la Unión Soviética ante las Comunidades Europeas (Sodupe, 1987; Zubok, 1996; Rey, 2005; Mueller, 2009). En dicha argumentación, como señala Emilia Robin en su artículo sobre el caso francés del presente dosier, se combinaban preocupaciones geopolíticas, herencias históricas y consideraciones ideológicas estrechamente relacionadas con la experiencia soviética.

Además de la identificación con la política soviética, la actitud de los partidos comunistas de Europa occidental ante la integración europea, como evidencia la historiografía sobre el caso francés y el italiano (Callot, 1988; Brake, 2007; Robin, 2009; Cruciani, 2010; Azam, 2011; Cirulli, 2016), era también producto de la percepción del mundo de posguerra que, desde las distintas realidades nacionales y desde la propia génesis histórica de los distintos partidos, impregnaba de forma generalizada la cultura política del comunismo. La visión comunista del proceso comunitario se integraba por tanto en el contexto más amplio de una Europa de posguerra que era contemplada, desde la teoría marxista y las aportaciones leninistas, como el escenario de una lucha de clases en la última fase de desarrollo imperialista del capitalismo. La hegemonía estadounidense en el bloque occidental aportaba también argumentos para un discurso ideológico opuesto a la integración europea al ser considerada esta como el fruto de los designios de la potencia norteamericana para la defensa del capitalismo y la agresión contra la Unión Soviética.

La unanimidad en el relato comunista occidental sobre la integración comunitaria comenzó a resquebrajarse desde finales de la década de 1960 como consecuencia de lo que historiográficamente suele considerarse como el tránsito del anti europeísmo ideológico al anti europeísmo crítico (Cirulli, 2016). Ya en la década de los setenta, en una sensible diferenciación con otros partidos, el Partido Comunista Italiano (PCI) y el Partido Comunista de España (PCE), cambiaron significativamente su discurso político al aceptar el proyecto europeo desde un europeísmo crítico que contemplaba la integración europea como una realidad ineludible en cuyo marco poder abordar sus proyectos de transformación social mediante la colaboración entre las fuerzas de la izquierda europea. Posteriormente, la evolución del relato comunista favorable a la integración se reforzó en el caso del comunismo español e italiano, mientras que el Partido Comunista Francés (PCF) mantuvo sus reticencias, instalando su discurso europeo en un euroescepticismo avant la lettre, aunque algo alejado 
del rechazo de años anteriores, y otros partidos, como el portugués (PCP), permanecieron, prácticamente sin fisuras, en sus posiciones anteriores.

Las divergencias de las políticas europeas en el seno del comunismo occidental durante la década de 1970 han sido objeto de una amplia atención historiográfica enmarcada, por lo general, en el análisis del denominado eurocomunismo, corriente crítica con la Unión Soviética desarrollada durante la segunda mitad de dicha década con especial repercusión en las políticas del PCI y el PCE y en mucha menor medida en el PCF (Timmermann, 1979; Bell, 1996; Di Giacomo, 2010; Treglia, 2011; Buton, 2011; Lazar, 2011; Dörr, 2014). En relación más estricta con la integración europea, los distintos casos nacionales han sido también abordados de manera individualizada o comparativa desde la perspectiva de la europeización, es decir, del condicionamiento de las políticas no solo europeas sino también nacionales de los distintos partidos como consecuencia del proceso de integración (Levesque, 1987; Dunphy, 2004; Forner y Senante, 2020) así como desde la perspectiva de la tensión entre la ideología anticapitalista y las estrategias políticas nacionales (Charalambous, 2013; Forner y Senante, 2019).

El eurocomunismo no llegó a dejar un cuerpo doctrinal ni supuso una estrategia común europea de los partidos comunistas occidentales ya que su objetivo se centraba en la afirmación de las vías nacionales hacía el socialismo. Durante la etapa eurocomunista se produjo un auge electoral del comunismo occidental en su conjunto, más allá de su relación más o menos estrecha con dicha tendencia. Dicho auge permitía presagiar en algunos países cierta convergencia futura con la socialdemocracia e incluso un desbordamiento de la misma, derivado de la apuesta por la vía democrática y del distanciamiento de la política soviética. Pero el avance electoral del comunismo resultó, sin embargo, muy efímero y se fue desvaneciendo desde comienzos de la década de 1980 en contraposición al avance de la socialdemocracia durante esos años (Forner y Senante, 2015). Por lo demás, el eurocomunismo no fue una tendencia aceptada por todos los partidos occidentales ya que aquellos partidos más férreamente vinculados a la Unión Soviética se mantuvieron en posiciones ortodoxas y obtuvieron el apoyo de esta en contraposición a las suspicacias generadas por la tendencia eurocomunista en la dirigencia soviética (Waller, 1989). Paradójicamente, la llegada de Gorbachov al poder a mediados de los ochenta pareció confirmar los planteamientos eurocomunistas y significó un cambio en la actitud de la Unión Soviética hacia la Comunidad Europea que se acomodaba con las opciones favorables a la integración de algunos partidos comunistas occidentales. 
El artículo de Emanuele Treglia y Ricardo Martín de la Guardia da cuenta de ese significativo cambio en la política soviética y de su percepción por parte de los dirigentes comunitarios. Con el abandono de la hostilidad hacia el proceso de integración, que había caracterizado la política exterior soviética desde los años cincuenta, la política de Gorbachov produjo un acercamiento hacia la Comunidad Europea que podía suponer una superación de la división de Europa desde el comienzo de la guerra fría. Sus propuestas a favor de una «casa común» europea y su disposición al diálogo y a la negociación tuvieron eco en las instancias comunitarias llegándose a normalizar las relaciones entre la Comunidad y el Consejo de Ayuda Mutua Económica de la URSS y otros países del Este. La complacencia occidental con las reformas de Gorbachov no se correspondía, sin embargo, con el respaldo decreciente de la opinión pública soviética hacia sus reformas. La reestructuración gorbachoviana chocaba con la resistencia de los sectores ortodoxos del PCUS sin producir efectos positivos en las condiciones sociales y el nivel de vida de la población y tampoco fue muy bien recibida, con las únicas excepciones relevantes del PCI y del PCE, por una buena parte del comunismo occidental.

Más allá de sus tendencias ortodoxas o renovadoras la perestroika tuvo un impacto desestabilizador sobre todos los partidos comunistas occidentales. En el caso de los partidos más dogmáticos y sovietizados se planteaba el riesgo de una ruptura del cordón umbilical que los unía a la URSS a no ser que entrasen en un proceso de cambio de sus antiguas convicciones. En la mayoría de los casos ese cambio fue meramente retórico ya que, en la práctica, no se alteraron sus pautas organizativas e ideológicas y mantuvieron su rechazo al proceso de integración europea. Los partidos que habían adoptado políticas renovadoras de inspiración eurocomunista marcadas por la independencia respecto al PCUS reforzaron durante la segunda mitad de la década de 1980 dichas políticas y apostaron decididamente por el apoyo a las transformaciones que estaba experimentando la Comunidad Europea con la aprobación del Acta Única pero no se libraron de un declive que afecto a todo el espacio político del comunismo occidental desde comienzos de los ochenta.

La descomposición del bloque soviético entre 1989 -derrumbe del Muro de Berlín-y 1991-desaparición de la Unión Soviética- agudizó la crisis de los partidos comunistas de Europa occidental abriendo un proceso de transformación de algunos de ellos (Bosco, 2000) y provocando en algunos casos su desaparición. En el nuevo rumbo emprendido por dichas formaciones ya no se disponía del aglutinante internacional suministrado anteriormente por la existencia de la esfera soviética. Esa orfandad de un aglutinante internacional iba a ser suplida sin embargo, en el marco de la integración comunitaria, por un 
discurso anti europeísta o euroescéptico como nuevo elemento identitario que ha posibilitado, para el ámbito europeo y en posiciones de extrema izquierda frente a la izquierda socialdemócrata, la cohesión transnacional entre los antiguos partidos comunistas y las nuevas formaciones políticas anticapitalistas a las que ha dado paso la desaparición, el debilitamiento o la mutación de dichos partidos (Rodríguez-Aguilera de Prat, 2012).

Los cambios operados en el espacio político situado a la izquierda de la socialdemocracia desde comienzos de la década de 1990 han dado lugar a una amplia y variada literatura en la que ha quedado relativizada la importancia de los partidos comunistas de Europa occidental en la escena política al quedar estos inmersos en un nuevo universo postcomunista junto a las formaciones de la «nueva izquierda» o izquierda radical europea (Backes y Moreau, 2008; Heine, 2009; De Waele y Seiler, 2012; Escalona y Vieria, 2013; Fagerholm, 2017). Sin embargo, estos siguen teniendo una presencia significativa en el conjunto de la izquierda formando parte incluso recientemente, como en el caso de España, de coaliciones gubernamentales o dando su apoyo, como en Portugal, a gobiernos socialistas en el marco de coaliciones parlamentarias.

Por lo que se refiere a la integración europea la evolución del comunismo occidental tras la descomposición del bloque soviético se ha traducido en una nueva unanimidad similar a la que se dio durante los primeros años del proceso comunitario. En realidad, solo dos de los más importantes partidos comunistas europeos, el PCI y el PCE, mantuvieron una neta posición europeísta hasta la implosión de los regímenes comunistas de Europa del Este. Las consecuencias extraídas de dicha implosión tuvieron un notable impacto en la evolución del comunismo italiano que en el XX Congreso, celebrado en Rímini a comienzos de 1991, decidió la disolución del PCI y la creación del Partito Democratico de la Sinistra, posteriormente integrado en la Internacional Socialista. Un sector minoritario del antiguo PCI se aglutinó en una nueva formación política de carácter residual, «Refundación Comunista» (RF), partido liderado por Armando Cossutta, que permaneció fiel a la tradición comunista. Frente a la transformación del PCI en un nuevo partido de signo socialdemócrata y plenamente europeísta, el apoyo de RF a la Comunidad Europea experimentó un retroceso en comparación con las posiciones anteriormente mantenidas por el comunismo italiano alineándose al respecto con los partidos comunistas francés, portugués y griego, que al igual que una mayoría de otros minúsculos partidos, siguieron manteniendo su denominación, simbología e identidad política.

Desaparecido el PCI, solo el PCE entre los partidos comunistas más relevantes de Europa occidental mantuvo por el momento un pleno apoyo a la 
integración europea. El comunismo español había iniciado en la década de 1970 un sensible cambio en su política europea que culminó con el apoyo al Tratado de Adhesión de España a las Comunidades Europeas en 1985. Pero tras la desaparición de la Unión Soviética, y en una coyuntura tan relevante para la profundización comunitaria como la enmarcada por la aprobación del Tratado de Maastricht, el PCE reorientó su política europea hacia posiciones muy críticas con la Unión Europea. En el artículo de este dosier dedicado a la trayectoria de la política europea del PCE se analiza dicha trayectoria en su relación con el auge y el declive electoral del comunismo español hasta la crisis económica de 2008.

El nuevo viraje en la política europea del comunismo español fue impulsado por Julio Anguita, elegido Secretario General del PCE en 1988. La reorientación hacia la izquierda propiciada por Anguita se basaba en una nueva consideración del orden mundial que, tras la desaparición del bipolarismo, habría dado paso a la completa hegemonía del gran capital y del imperialismo americano. En ese contexto internacional el PCE reafirmó su seña de identidad comunista reforzando sus relaciones con partidos como el francés (PCF) y el portugués (PCP) y criticando abiertamente el cambio ideológico del partido comunista italiano por su evolución hacia la socialdemocracia. Tras el relativo auge electoral del PCE, propiciado en parte por el retroceso del respaldo público a la integración europea como consecuencia de la crisis económica de los primeros años noventa, el comunismo español entró en un prolongado declive. En el artículo de Salvador Forner y Heidy-Cristina Senante se analiza en qué medida pudo influir en dicho declive el cada vez mayor distanciamiento entre la política europea del PCE, muy crítica con el modelo de integración de Maastricht, y una opinión pública que, por el contrario, acrecentaba su apoyo al mismo.

El abandono del bucle europeísta que el PCE había iniciado en 1972 lo aproximó de nuevo a partidos que, como el francés o el portugués, se habían mantenido, con mayor o menor intensidad, en posiciones críticas o de rechazo hacia el proceso comunitario. El análisis del caso francés, a cargo de Emilia Robin, muestra esa continuidad de la política europea del PCF enmarcada en el rechazo a los Tratados Europeos sometidos a referéndum en 1992 y 2005, Tratado de la Unión Europea y Tratado Constitucional. No obstante, la naturaleza de ese rechazo ha variado sensiblemente a lo largo de dicho período. El posicionamiento del comunismo francés contra el proceso comunitario tuvo en sus orígenes motivaciones similares a las del resto de partidos comunistas de Europa occidental pero con una mayor carga de defensa de la soberanía nacional y de identificación con la Unión Soviética en el marco de la guerra 
fría. A partir de comienzos de la década de 1990 el soberanismo y las razones geopolíticas fueron perdiendo peso reforzándose, por el contrario, la crítica ideológica de la propia naturaleza de la integración. Como muestra el análisis efectuado por Emilia Robin, esa evolución fue a la vez causa y consecuencia de la mutación interna experimentada por el PCF tras el final de la guerra fría, de la recomposición ideológica en el campo de la izquierda francesa y del proceso de europeización derivado de la participación en las instituciones comunitarias.

Con cierto paralelismo con el comunismo francés, el caso del partido comunista portugués, analizado por Carlos Cunha, destaca por su constante y prolongada oposición al proceso de construcción europea y por el rechazo de la pertenencia de Portugal a la Unión Europea. Cunha ofrece en su artículo un pormenorizado análisis de las posiciones críticas mantenidas por el PCP en las distintas etapas del proceso de integración. El autor profundiza especialmente en el estudio de los últimos treinta años, desde Maastricht hasta la actualidad, resaltando la trascendencia que en la reafirmación de los argumentos del PCP contra la construcción europea, desde sus orígenes hasta la actualidad, ha tenido la crisis del euro. Las políticas de ajuste y austeridad por parte de las instituciones comunitarias exacerbaron las críticas que desde siempre había mantenido el PCP frente a la Unión Europea lo que permitió al comunismo portugués esgrimir las dificultades que atravesó el país en dicha coyuntura como la prueba determinante de que su posición ante la Unión Europa había sido siempre la correcta.

La Unión Europea ha sido y es entendida por el PCP como una amenaza para los derechos de los trabajadores, para el bienestar social, para la democracia y para la soberanía nacional. El comunismo portugués ha centrado su crítica a la UE en análisis económicos que muestran, a su juicio, cómo la pertenencia a la Europa comunitaria ha tenido, en general, un impacto negativo perjudicando gravemente los intereses nacionales portugueses. El PCP considera que las políticas de la UE favorecen la regresión social, la concentración de riqueza, la desinversión pública, las privatizaciones, mayor dependencia y deuda, el deterioro de la democracia y la falta de respeto a la soberanía nacional. El PCP se enorgullece de haberse opuesto a la adhesión de Portugal a la CEE, y propone, incluso, una salida ordenada de Portugal de la Unión Económica y Monetaria y elogia la decisión del pueblo británico de abandonar la Unión Europea. 


\section{Bibliografía}

AZAM, N. (2011). La intégration européenne dans les programmes du Parti Communiste Français depuis 1979. Strasbourg: Congrès AFSP.

BACKES, U y MOREAU, P. (2008). Communist and Post-Communist Parties in Europe. Göttingen: Vandenhoeck and Ruprecht. Disponible en: https://doi. org/10.13109/9783666369124.463

BELL, David (1996). Western Communist Parties and the European Union. En John Gaffney. Political Parties and European Union, pp. 220-234. Londres: Routledge.

BOSCO, A. (2000). Comunisti. Transformazione di partito in Italia, Spagna e Portogallo. Bolonia: Il Mulino.

BRACKE, M. (2007). From the Atlantic to the Urals? Italian and French communism and the question of Europe, 1956-1973. Journal of European Integration History, 13 (2), 33-53.

BUTON, Philippe (2011): El Partido Comunista Francés frente al eurocomunismo: un partido en la encrucijada. Historia del Presente, 18, II/2011, pp. 9-23.

CALLOT, E. F. (1988). The French Communist Party and Europe: the idea and its implementation (1945-1985). European Journal of Political Research, 16 (3), 301-316.

CHARALAMBOUS, G. (2013). European Integration and the Communism Dilemma. Farnham: Ashgate.

CIRULLI, C. G. (2012). La sinistra italiana e il proceso d'integrazione europea. Lucca: Institute for Advanced Studies.

CRUCIANI, S. (2010). Histoire d'une rencontré manquée: PCF et PCI au défi de la construction communautaire (1947-1964). Cahiers d'histoire. Revue d'histoire critique, n. $^{\mathrm{o}} 112-113,57-76$.

DE WAELE, J. M. y SEILER, D. (2012). Les partis de la gauche anticapitaliste en Europe. París: ECONOMICA.

DI GIACOMO, Michelangela (2010). Identità eurocomunista: la traiettoria del PCE negli anni Settanta. Studi Storici, 2, pp. 461-494.

DÖRR, N. R. (2014). Eurokommunismus als Teil des historichen Kommunismusforschung. Potsdam: Docupedia-Zeitgeischichte. Disponible en: https://bit.ly/2TXzmZt

DUNPHY, R. (2004). Contesting Capitalism? Left parties and European Integration. Manchester: Manchester University Press.

ESCALONA, F. y VIEIRA, M. (2013). La gauche radicale en Europe ou l'émergence d'une famille de partis. Fondation Jean Jaurès / Observatoire de la vie politique, $\mathrm{n}{ }^{\circ}$ 2. Disponible en: https://jean-jaures.org/sites/default/files/note-obs-vp-2.pdf

FAGERHOLM, A. (2017). What is left for the radical left? A comparative examination of the policies of radical left parties in western Europe before and after 1989. Journal of Contemporary European Studies, vol. 25, 1, 16-40. 
FORNER, S. y SENANTE, H.C. (2015). La crisis del comunismo en Europa occidental: entre el eurocomunismo y el colapso del bloque soviético. Historia y Política, 33, 303-331.

FORNER, S. y SENANTE, H.C. (2019). La política europea del PCE (1972-1999): del viraje europeísta al euroescepticismo. Historia y Política, 41, 335-366.

FORNER, S. y SENANTE, H.C. (2020). El relato comunista de la integración europea: ideología y estrategia política. Revista de Estudios Políticos, 187, 137-165.

HEINE, Sophie (2009). Une gauche contre l'Europe? Bruselas: Université de Bruxelles.

LAZAR (2011). El eurocomunismo, objeto de historia. Historia del Presente, n. ${ }^{\circ}$ 18, II/2011, pp. 59-66.

LEVESQUE, Jacques (1987). Le parti communiste italien, l'URSS et l'ordre international. Le cheminement du PCI depuis 1975. Revue Française de Science Politique, vol. 37, n. ${ }^{\circ} 2$.

MUELLER, W. (2009). The Soviet Union and Early West European Integration, 1947-1957. Journal of European Integration History, 15 (2), 67-85.

REY, M. P. (2005). Le retour à l'Europe? Les décideurs soviétiques face à l'intégration ouest-européenne, 1957-1991. Journal of European Integration History, 11, 7-27.

ROBIN, E. (2009). Anti-européens et euroconstructifs: les communistes français et l'Europe (1945-1979). Les Cahiers Irice, 2, 4, 49-67.

RODRÍGUEZ-AGUILERA DE PRAT, C. (2012). Euroescepticismo, eurofobia y eurocriticismo. Los partidos radicales de la derecha y la izquierda ante la UE. Barcelona: Huygens.

SODUPE, K. (1987). La visión soviética de la integración europea. El caso de la CEE, 1957-1969. Bilbao: Universidad del País Vasco.

TIMMERMANN, Barbara (1979). Dokumente zum Eurokommunismus, Frankfurt a.M., Verlag Moritz Diesterweg.

TREGLIA, Emanuele (2011). Un partido en busca de identidad. La difícil trayectoria del eurocomunismo español. Historia del Presente, 18, II/2011, pp. 25-41.

WALLER, Michael (1989). Les partis communistes ouest-européens à l'heure Gorbatchev (Dossier documental). Paris: La Documentation Française, 608.

ZUBOK, V. (1996). The Soviet Union and European Integration from Stalin to Gorbachev. Journal of European Integration History, 2, 85-98. 